
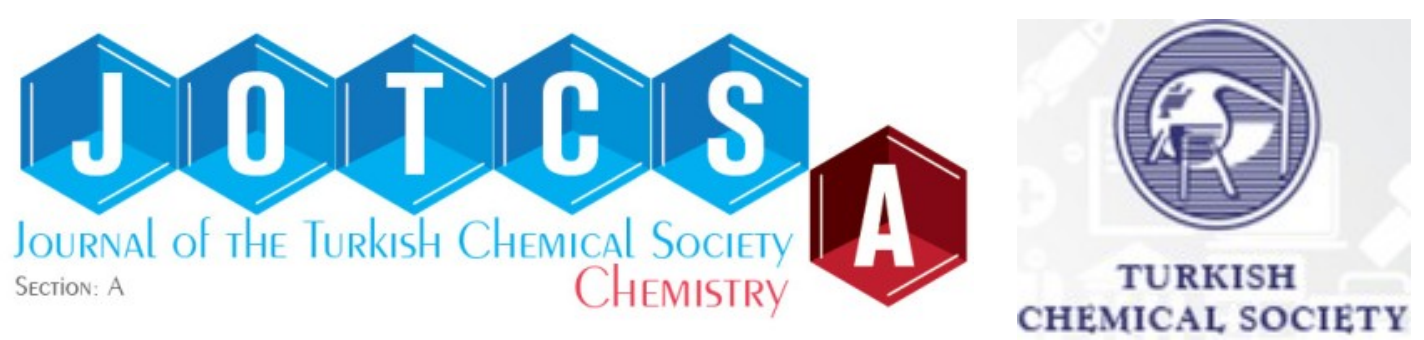

\title{
A Near-infrared Benzothiazole-based Chemodosimeter for Rapid and Selective Detection of Hydrogen Sulfide
}

\author{
Safacan KOLEMEN ${ }^{1,2,3 *}$ iD \\ ${ }^{1}$ Department of Chemistry, Faculty of Science, Koc University, Sariyer, Istanbul 34450, Turkey \\ 2Surface Science and Technology Center (KUYTAM), Koc University, Sariyer, Istanbul 34450, Turkey \\ ${ }^{3}$ Boron and Advanced Materials Application and Research Center, Koc University, Sariyer, Istanbul 34450, \\ Turkey
}

\begin{abstract}
Hydrogen sulfide $\left(\mathrm{H}_{2} \mathrm{~S}\right)$ is a biologically relevant gaseous molecule, which involves in a wide variety of physiological and pathological processes. Thus, detection of $\mathrm{H}_{2} \mathrm{~S}$ is highly valuable in order to clarify its complex roles. In this study, a new benzothiazole-based donor-acceptor type $\mathrm{H}_{2} \mathrm{~S}$ selective chemodosimeter (HP-1) was synthesized and its $\mathrm{H}_{2} \mathrm{~S}$ detection capabilities were investigated in aqueous solutions. HP-1 exhibited a red-shifted absorption signal at $530 \mathrm{~nm}$ and a near-infrared (NIR) fluorescence peak at $680 \mathrm{~nm}$ as a result of enhanced intramolecular charge transfer (ICT) in the presence of $\mathrm{H}_{2} \mathrm{~S}$, which enabled a selective and very rapid ratiometric fluorescent detection. HP-1 was also showed to be highly sensitive toward $\mathrm{H}_{2} \mathrm{~S}$ with a very low limit of detection value.
\end{abstract}

Keywords: Fluorescence, hydrogen sulfide, benzothiazole, near-infrared imaging chemodosimeters.

Submitted: January 05, 2021. Accepted: April 12, 2021.

Cite this: Kolemen S. A near-infrared benzothiazole-based chemodosimeter for rapid and selective detection of hydrogen sulfide. JOTCSA. 2021;8(2):567-78.

DOI: https://doi.org/10.18596/jotcsa.853370.

*Corresponding author. E-mail: skolemen@ku.edu.tr.

\section{INTRODUCTION}

Hydrogen sulfide $\left(\mathrm{H}_{2} \mathrm{~S}\right)$ is an important gasotransmitter along with carbon monoxide and nitric oxide in living cells, which is endogenously produced from cysteine and cysteine derivatives in reactions that are catalyzed by cystathionine $\beta$ synthase (CBS), cystathionine $\gamma$-lyase (CSE) and 3mercaptopyruvate sulfurtransferase (MST) (1-4). $\mathrm{H}_{2} \mathrm{~S}$ involves in fundamental signaling pathways and consequently plays crucial roles in various physiological processes such as cell growth, neurotransmission, insulin secretion, regulation of the redox balance, inflammation, angiogenesis and apoptosis $(3,5)$. However, mismanagement of intracellular $\mathrm{H}_{2} \mathrm{~S}$ level is directly associated with the formation of serious health problems including Alzheimer's disease, Down syndrome, diabetes, hepatic cirrhosis, and cardiovascular disorders (58 ). It is also well-established that CSE and CBS enzymes are overexpressed in certain cancer cells, which makes $\mathrm{H}_{2} \mathrm{~S}$ a significant marker for cancer diagnosis $(9,10)$. Thus, it is critical to detect and track dynamic $\mathrm{H}_{2} \mathrm{~S}$ fluxes with high selectivity and sensitivity in their native environment. Conventional detection approaches mostly rely on electrochemical analyses, gas chromatography, and metal-induced precipitation techniques, which are limited mainly due to the low sensitivity and lack of real-time imaging capability (11-13). To that end, fluorescence imaging is a highly promising tool as it offers spatial and temporal resolution, high selectivity/sensitivity, nondestructive nature, in situ detection, and cheap instrumentation (14-16). In the design of $\mathrm{H}_{2} \mathrm{~S}$ selective fluorescent agents, the most popular 
approach is to employ reaction-based probes (chemodosimeters) as a result of high reactivity of $\mathrm{H}_{2} \mathrm{~S}$. Accordingly, plenty of chemodosimeters utilizing a wide variety of reactions such as reduction of azide or nitro to amine, nucleophilic addition, thiolysis of $m$-dinitrophenyl ether and cleavage of dinitrobenzenesulfonyl moiety have been successfully reported so far in order to satisfy selective optical detection (15-19). However, majority of the reaction-based probes still suffer from the emission signals below $650 \mathrm{~nm}$, which can be absorbed by biomolecules and results in autofluorescence. On the other side, near-IR (NIR) emitting probes are quite attractive as the NIR signal does not interfere with the biological fluorophores as well as allows deeper tissue penetration (20). Thus, a great deal of effort has been put to develop $\mathrm{H}_{2} \mathrm{~S}$-selective NIR chemodosimeters, $(15,20-23)$, however there are still some challenges need to be addressed in order to improve the impact of NIR probes such as slow response rates, low fluorescence quantum yields and small Stokes shifts.

Donor- $\pi$-acceptor (D- $\pi-A$ ) dyes have attracted great interest as fluorescent probes in recent years since they possess strong NIR emission signals and large Stokes' shifts in aqueous solutions, and they can be easily obtained through a well-established chemistry (24-27). In a typical design approach, a phenol group, which acts as a donor, is attached to acceptor moieties, which results in a $\pi$-conjugated system. Deprotonation of the phenol in physiological conditions or removing the cage group on the phenol with an analyte of interest yields a phenolate that initiates intramolecular charge transfer (ICT) process by triggering the donation of $\pi$-electrons from phenolate to conjugated acceptor units (24). This causes a remarkable red-shift in the absorption signal of the probe and generates a strong NIR emission, which allows both ratiometric and OFF-ON type detection (24). Benzothiazole is among the promising acceptor units, which have been used successfully in the design of $D-\pi-A$ type chemodosimeters for imaging of several analytes $(23,28,29)$. In this study, a $\mathrm{H}_{2} \mathrm{~S}$ selective benzothiazole-based chemodosimeter (HP-1) (Figure 1) was developed as a $(D-\pi-A)$ type probe and its $\mathrm{H}_{2} \mathrm{~S}$ detection capabilities were evaluated in detail by UV-Vis and fluorescence spectroscopies in aqueous solutions.

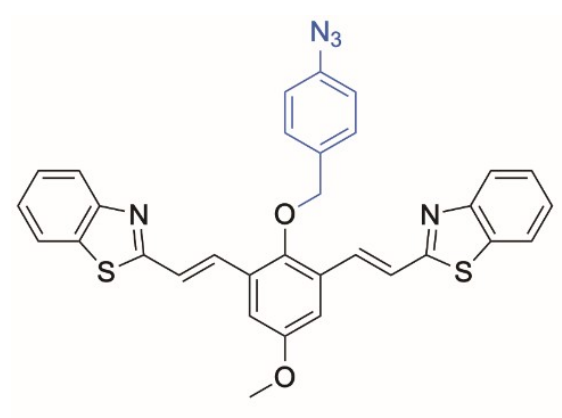

(HP-1)
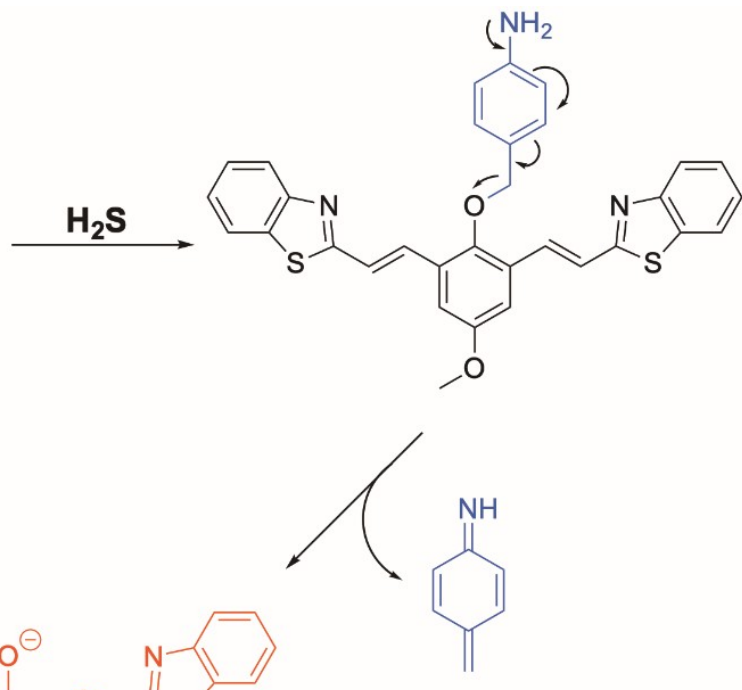

Figure 1. Structure of HP-1 and its activation mechanism in the presence of $\mathrm{H}_{2} \mathrm{~S}$.

\section{EXPERIMENTAL}

\section{Chemicals and Apparatus}

Reagents were purchased from Sigma-Aldrich or Merck and used without further purification. All dry solvents used in reactions were directly obtained from the Mbraun MBSPS5 solvent drying system. Sodium sulfide nonahydrate $\mathrm{Na}_{2} \mathrm{~S} \cdot 9 \mathrm{H}_{2} \mathrm{O}$ was purchased from Sigma-Aldrich and stored at 2-8 ${ }^{\circ} \mathrm{C}$. Deuterated solvents were purchased from Eurisotop and used as received. Column chromatography was performed by using thickwalled glass columns and silica gel (Merck 230-400 mesh). Thin layer chromatography (TLC Merck Silica Gel 60 F254) was performed by using commercially prepared $0.25 \mathrm{~mm}$ silica gel plates 
and visualization was provided by UV lamp. The relative proportions of solvents in chromatography solvent mixtures refer to the volume: volume ratio.

\section{Instruments}

${ }^{1} \mathrm{H}$ and ${ }^{13} \mathrm{C}$ NMR spectra were recorded on a Bruker Avance III Ultrashield $500 \mathrm{MHz}$ NMR spectrometer using $\mathrm{CDCl}_{3}$ or $\mathrm{d}_{6}$-DMSO as the solvents. Chemical shifts are reported in ppm. Coupling constants ( $\mathrm{J}$ ) are reported in hertz $(\mathrm{Hz})$, and the spin multiplicities were specified by the following symbols: s (singlet), d (doublet), t (triplet), and $\mathrm{m}$ (multiplet). NMR spectra were processed with MestReNova software. UV-Visible spectra were acquired on a Shimadzu UV-3600 UV-Vis-NIR spectrophotometer. Fluorescence spectra were collected on an Agilent Cary Eclipse spectrophotometer. Fluorescence quantum yield of the samples were investigated by using a fluorescence spectrometer (FLS 1000, Edinburgh Instruments) with an integrating sphere accessory. Mass spectra were recorded on Waters Synapt G1 High-Definition mass spectrometer.

\section{Synthesis}

1-azido-4-(bromomethyl)benzene (2) (30) and compound (4) (23) were synthesized according to literature reports (Figure 2).

\section{Synthesis of $H P-1$}

Compound 4 (50 mg, $0.12 \mathrm{mmol}$ ) was dissolved in dry $\mathrm{ACN}(10 \mathrm{~mL})$ and $\mathrm{K}_{2} \mathrm{CO}_{3}(636 \mathrm{mg}, 4.6 \mathrm{mmol})$ was added to the resulting solution. The solution was stirred at room temperature for 15 minutes and compound 2 ( $31 \mathrm{mg}, 0.15 \mathrm{mmol}$ ) was added to the reaction mixture. The reaction was stirred overnight at room temperature. The crude mixture was diluted with DCM (100 mL) and washed with brine $(100 \mathrm{~mL})$. Organic layer was separated and dried over $\mathrm{Na}_{2} \mathrm{SO}_{4}$. The crude product was purified by column chromatography on silica gel (nhexane/EtOAc, 2/1) to give yellow-white solid (58\% yield, $38 \mathrm{mg}) .{ }^{1} \mathrm{H}$ NMR $\left(500 \mathrm{MHz} \mathrm{CDCl}_{3}\right.$, ppm) $\delta 8.02(\mathrm{~d}, J=8.1 \mathrm{~Hz}, 2 \mathrm{H}), 7.89(\mathrm{~d}, J=8.0$ $\mathrm{Hz}, 2 \mathrm{H}), 7.74(\mathrm{~d}, J=16.3 \mathrm{~Hz}, 2 \mathrm{H}), 7.51-7.39$ $(\mathrm{m}, 8 \mathrm{H}), 7.20(\mathrm{~s}, 2 \mathrm{H}), 7.03(\mathrm{~d}, J=8.1 \mathrm{~Hz}, 2 \mathrm{H})$, $4.87(\mathrm{~s}, 2 \mathrm{H}), 3.89(\mathrm{~s}, 3 \mathrm{H}) .{ }^{13} \mathrm{C}$ NMR $(126 \mathrm{MHz}$, $\left.\mathrm{CDCl}_{3}, \mathrm{ppm}\right) \delta 166.9,156.3,153.9,149.6,140.5$, $134.3,132.7,132.1,130.9,130.7,126.4,125.7$, 124.2, 123.1, 121.6, 119.4, 112.8, 77.7, 55.7. HRMS m/z calc. for $\mathrm{C}_{32} \mathrm{H}_{23} \mathrm{~N}_{5} \mathrm{O}_{2} \mathrm{~S}_{2}: 574.1293[\mathrm{M}+\mathrm{H}]$ +; found: 574.1371 .

\section{Photophysical measurements}

Stock solution of HP-1 was prepared in DMF and then diluted with PBS $(\mathrm{pH}$ 7.4) to final concentrations before each measurement. $\mathrm{Na}_{2} \mathrm{~S} \cdot 9 \mathrm{H}_{2} \mathrm{O}$ stock solution was prepared in PBS $(\mathrm{pH}$ 7.4). $3 \mathrm{~mL}$ quartz cells were used, and the slit widths were set up as $10 \mathrm{~nm}$ for both emission and excitation.

\section{Fluorescence quantum yield calculation}

Fluorescence quantum yield of the sample was investigated by using a fluorescence spectrometer with an integrating sphere accessory. A continuous-wave xenon lamp was used as the excitation source and the emitted fluorescence was detected with a standard photomultiplier (PMT-900) covering a wavelength range of $200-900 \mathrm{~nm}$. During the measurements, the PMT was cooled down to $20{ }^{\circ} \mathrm{C}$ by using a built-in housing to reduce the undesired dark current noise.

For quantum yield measurement, an integrating sphere was placed inside the sample compartment of the spectrometer. Internal cavity of the sphere was coated with a PTFE-like material to enable a reflectance of approximately $>95 \%$ over the wavelength range between 400 and $1500 \mathrm{~nm}$ (250 and $2500 \mathrm{~nm}$ ). Prior to the experiments performed with the sample, the blank spectrum was measured by using the reference solvents (PBS $(\mathrm{pH} 7.4,50 \% \mathrm{DMF}))$. In order to cover a scattering range, the emission scans were started from $20 \mathrm{~nm}$ below the actual excitation wavelength $(510 \mathrm{~nm})$ and finished at $900 \mathrm{~nm}$. Furthermore, the step size and the integration time of the measurements were set to $1 \mathrm{~nm}$ and 0.2 seconds, respectively. After all the emission measurements of the samples and references were complete, the quantum yield of the sample was determined by using the Fluoracle $^{\circledR}$ software. The built-in analysis tool calculated the quantum yield (QY) by following Eq. (1).

$$
Q Y=\frac{E_{s}-E_{B}}{S_{B}-S_{s}}
$$

where $E_{S}\left(E_{B}\right)$ and $S_{S}\left(S_{B}\right)$ are the selected areas for the emitted and scattered signals of the sample (blank).

\section{Limit of detection (LOD) calculation}

The limit of detection was calculated according to formula given below, where $\mathrm{m}$ is the slope of the emission intensity at $680 \mathrm{~nm}$ versus $\mathrm{Na}_{2} \mathrm{~S}$ concentration graph and $s$ is the standard deviation of the 6 blank measurements. LOD was calculated according to Eq. (2).

$$
\text { LOD }=3 \mathrm{~s} / \mathrm{m}
$$




\section{RESULTS AND DISCUSSION}

In the design of HP-1, two benzothiazole acceptor units were conjugated to donor $p$-methoxyphenol core and a $\mathrm{H}_{2} \mathrm{~S}$-cleavable azido group was used as a cage moiety to mask the phenol. Removal of the cage group upon $\mathrm{H}_{2} \mathrm{~S}$-induced selective reduction of azide to amine causes a red-shift in both absorption and emission signals of HP-1, which reveals a ratiometric fluorescence sensor for detection of $\mathrm{H}_{2} \mathrm{~S}$ (Figure 1). Synthesis of HP-1 was depicted in Figure 2. Initially, 4-aminobenzyl alcohol was treated with $\mathrm{NaN}_{3}$ in the presence of
$\mathrm{NaNO}_{2}$ to get 4-azidobenzylalcohol (1). Then (1) was reacted with $\mathrm{PBr}_{3}$ and the cage unit 4azidobenzyl bromide (2) was obtained. For the probe core synthesis, commercially available 4methoxyphenol was formylated by running a Duff reaction to give 2,6-diformyl-4-methoxyphenol (3), which was then converted to (4) via Knoevenagel condensation. Finally, the cage unit (2) was attached to (4) in dry acetonitrile and HP-1 was attained in a moderate yield. HP-1 was characterized by ${ }^{1} \mathrm{H}$ NMR, ${ }^{13} \mathrm{C}$ NMR and highresolution mass spectrometry (HR-MS) (Figure S1S3).<smiles>Nc1ccc(CO)cc1</smiles>

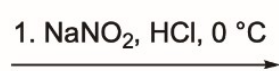
2. $\mathrm{NaN}_{3}$<smiles>[N-]c1ccc(CO)cc1</smiles>

(1)

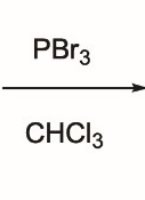

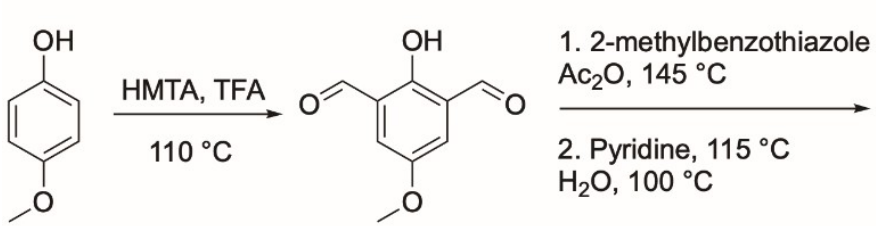

(3)<smiles>COc1cc(/C=C/c2nc3ccccc3s2)c(O)c(/C=C/c2nc3ccccc3s2)c1</smiles>

(4)<smiles>CCN(C)OCc1cc(/C=C/c2nc3ccccc3s2)c(OCc2ccc(N)cc2)c(/C=C/c2nc3ccccc3s2)c1</smiles>

Figure 2. Synthetic pathway for HP-1.

After completing the synthesis, the optical responses of HP-1 to $\mathrm{H}_{2} \mathrm{~S}$ were investigated with UV-Vis and fluorescence spectrophotometers in aqueous PBS solution ( $\mathrm{pH} 7.4,50 \%$ DMF) (Figures 3 and 4). In all the experiments, $\mathrm{H}_{2} \mathrm{~S}$ was generated in situ by adding $\mathrm{Na}_{2} \mathrm{~S}$ into a PBS buffered solution ( $\mathrm{pH} 7.4)$ as in the case of literature examples (15). The pKa of $\mathrm{H}_{2} \mathrm{~S}$ is 7 , thus the $\mathrm{Na}_{2} \mathrm{~S}$ solution in PBS at $\mathrm{pH} 7.4$ contains HSand $\mathrm{S}^{2-}$ anions in addition to $\mathrm{H}_{2} \mathrm{~S}$, which, in fact, mimics the speciation in the cellular environment (15). HP-1 exhibited strong but short wavelength absorption peak centered at $335 \mathrm{~nm}\left(\varepsilon=23100 \mathrm{M}^{-}\right.$ ${ }^{1} \mathrm{~cm}^{-1}$ ) as a result of blocked electron donation from donor core to acceptor units (Figure 3a). Upon treating HP-1 $(20 \mu M)$ with $\mathrm{Na}_{2} \mathrm{~S}(200 \mu \mathrm{M})$, absorption peak at $335 \mathrm{~nm}$ was slightly decreased and a concomitant red-shifted peak appeared at $530 \mathrm{~nm}\left(\varepsilon=6600 \mathrm{M}^{-1} \mathrm{~cm}^{-1}\right)$ with an isosbestic point at $420 \mathrm{~nm}$, which can be also detected by naked eye as colorless HP-1 solution turned to pale pink after the addition of $\mathrm{Na}_{2} \mathrm{~S}$. This result indicates that HP-1 reacts readily with $\mathrm{H}_{2} \mathrm{~S}$ and uncages the phenol, which switches on the ICT process. A gradual increase in the absorption signal at 530 $\mathrm{nm}$ was also determined when HP-1 was titrated with increasing concentrations of $\mathrm{Na}_{2} \mathrm{~S}(0-200 \mu \mathrm{M})$ (Figure 3b, Figure S5a). 
In the case of fluorescence measurements, a characteristic NIR emission signal at $680 \mathrm{~nm}$ appeared gradually as the $\mathrm{Na}_{2} \mathrm{~S}$ concentration (0$200 \mu \mathrm{M}$ ) increased (up to 130 -fold, $\varphi_{F}=11 \%$ ) upon excitation at newly formed absorption peak at $530 \mathrm{~nm}$ (Figure $4 \mathrm{a}, \mathrm{b}$, Figure S5b). When the excitation wavelength was adjusted to $420 \mathrm{~nm}$ (isosbestic point), emission peak of the parent HP1 at $470 \mathrm{~nm}$ was decreased and broad NIR fluorescence signal was observed between 650-
$750 \mathrm{~nm}$ with a maximum at $680 \mathrm{~nm}$ (Figure 4c), suggesting that HP-1 can act as a NIR ratiometric probe. Both changes in absorption and emission signals were accomplished in seconds, clearly indicating that HP-1 works much faster than most of the current $\mathrm{H}_{2} \mathrm{~S}$ selective probes and can rapidly detect $\mathrm{H}_{2} \mathrm{~S}$. It is also important to note that HP-1 exhibited a large Stokes' shift ( 150 nm) (Figure $4 d$ ), which is another critical parameter for a fluorescent probe.
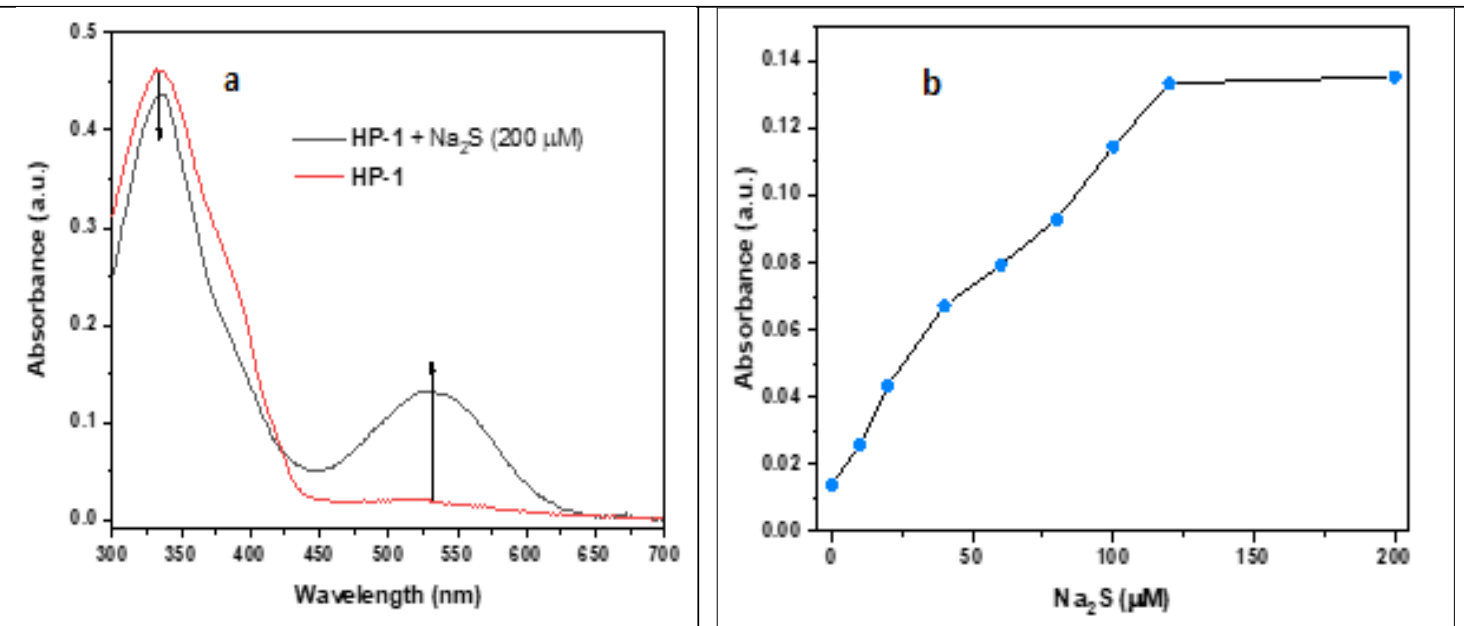

Figure 3. (a) Absorption spectra of HP-1 $(20 \mu \mathrm{M})$ before and after addition of $\mathrm{Na}_{2} \mathrm{~S}(200 \mu \mathrm{M})$ and (b) absorption signal of $\mathbf{H P - 1}(20 \mu \mathrm{M})$ at $530 \mathrm{~nm}$ in increasing $\mathrm{Na}_{2} \mathrm{~S}$ concentrations in PBS (pH 7.4, 50\% DMF).

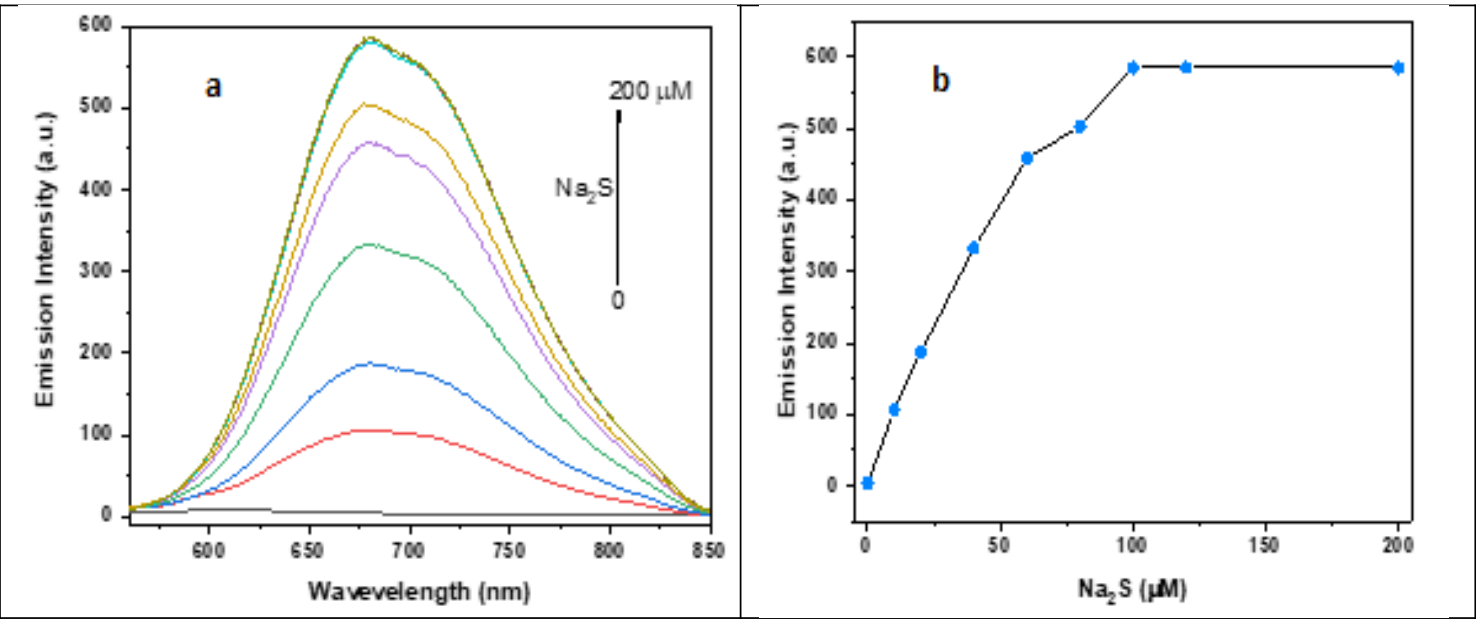




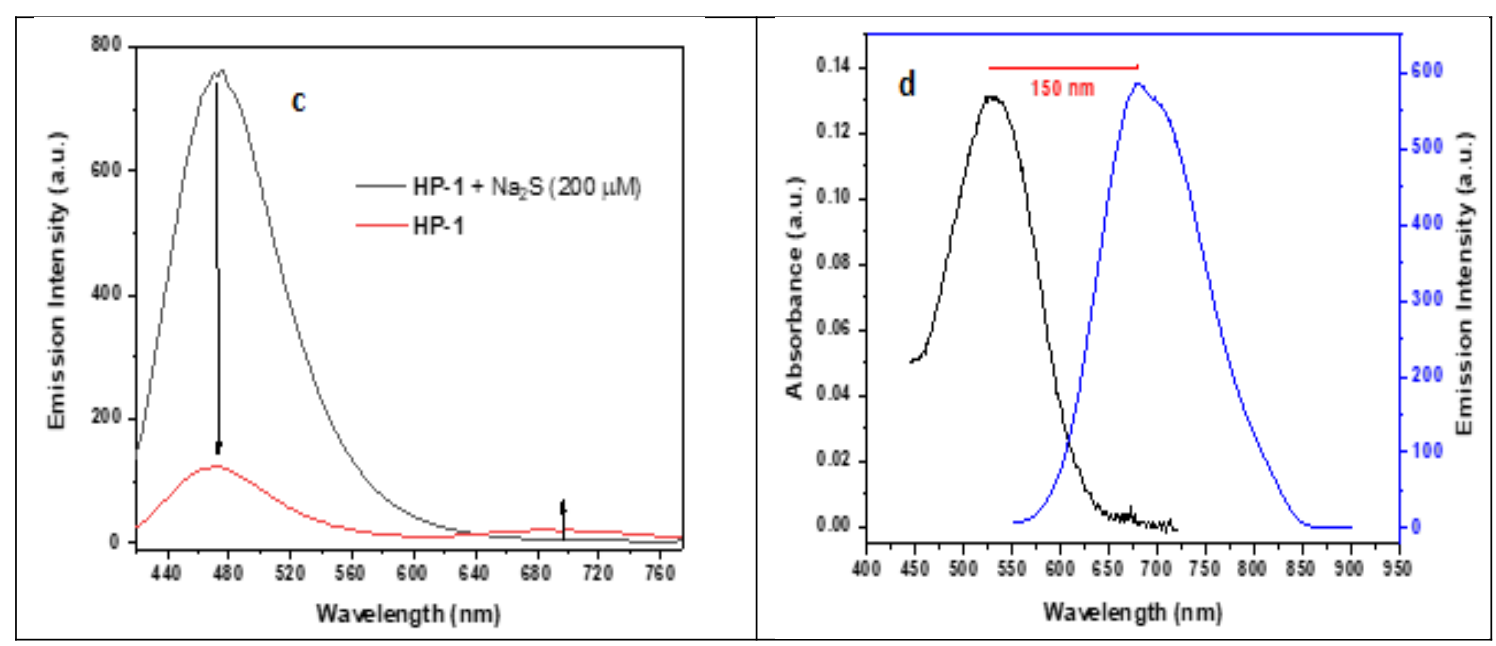

Figure 4. (a) Emission spectra of HP-1 (20 $\mu \mathrm{M})$ upon addition of increasing $\mathrm{Na}_{2} \mathrm{~S}$ concentrations and (b) the relationship between the emission intensities of $\mathbf{H P - 1}(20 \mu \mathrm{M})$ at $680 \mathrm{~nm}$ and the concentration of $\mathrm{Na}_{2} \mathrm{~S}$. Excitation wavelength is $530 \mathrm{~nm}$. (c) Emission spectra of HP-1 $(20 \mu \mathrm{M})$ before and after addition of $\mathrm{Na}_{2} \mathrm{~S}(200 \mu \mathrm{M})$. Excitation wavelength is $420 \mathrm{~nm}$. (d) The Stokes' shift of HP-1 (20 $\left.\mu \mathrm{M}\right)$ after addition of $\mathrm{Na}_{2} \mathrm{~S}(200 \mu \mathrm{M})$. Excitation wavelength is $530 \mathrm{~nm}$. All experiments were done in PBS (pH 7.4, 50\% DMF).

Next, the selectivity of HP-1 towards $\mathrm{H}_{2} \mathrm{~S}$ was checked by using biologically relevant nucleophilic species including bio-thiols such as glutathione (GSH), cysteine (Cys) and homocysteine (Hcy) as well as different metal ions. No detectable change was observed both in absorption and emission spectra (Figure 5), proving the high selectivity of
HP-1 for $\mathrm{H}_{2} \mathrm{~S}$ over other species. The sensitivity of HP-1 was measured by calculating the limit of detection (LOD) value and found to be as low as $0.64 \mu \mathrm{M}$. Finally, $\mathrm{H}_{2} \mathrm{~S}$-induced removal of the cage group and the release of compound 4 was confirmed by acquiring a high-resolution mass spectrum (Figure S4).

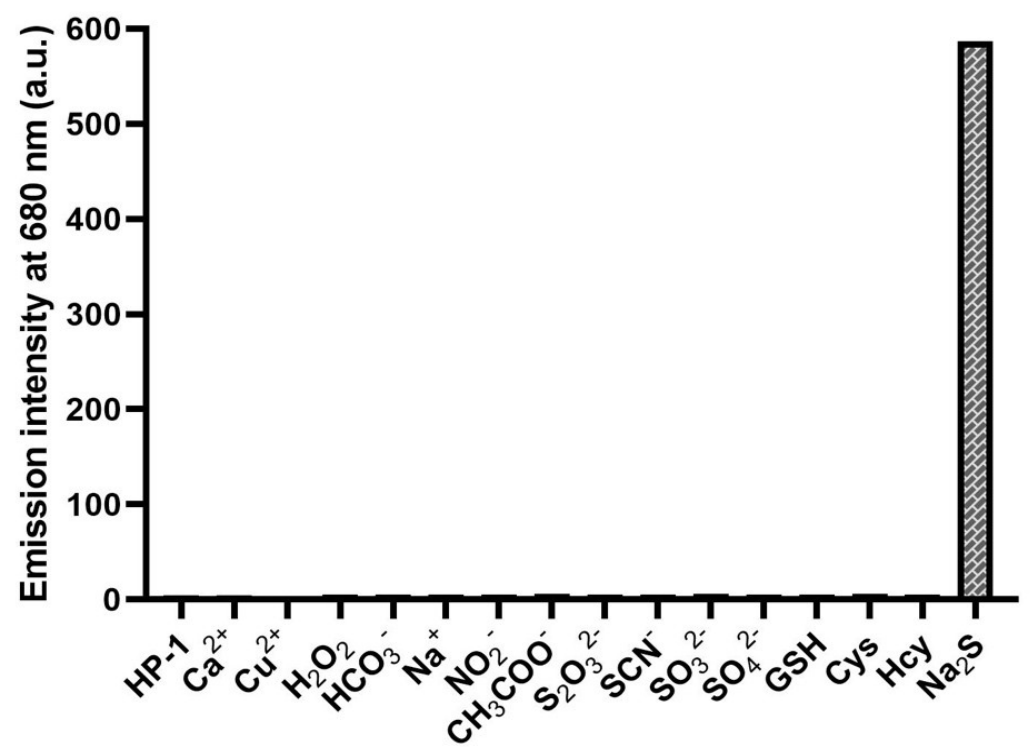

Figure 5. Emission intensities of HP-1 $(20 \mu \mathrm{M})$ in the absence and presence of different analytes in PBS ( $\mathrm{pH} 7.4,50 \% \mathrm{DMF})$. $\mathrm{Na}_{2} \mathrm{~S}$ concentration was $200 \mu \mathrm{M}$. All other analyte concentrations were set to $1 \mathrm{mM}$.

\section{CONCLUSION}

In summary, an easily accessible $\mathrm{H}_{2} \mathrm{~S}$-selective benzothiazole-based chemodosimeter (HP-1) was synthesized and its molecular structure as well as optical responses to $\mathrm{H}_{2} \mathrm{~S}$ were characterized. Upon addition of $\mathrm{Na}_{2} \mathrm{~S}, \mathbf{H P - 1}$ exhibited a $195 \mathrm{~nm}$ bathochromic shift in the absorption signal and $a$ 
noticeable concentration dependent increase in the NIR emission at $680 \mathrm{~nm}$ as a result of enhanced ICT process, which was triggered by the removal of the azido cage group. Remarkably, all of these changes in photophysical parameters were realized in seconds with high sensitivity and selectivity towards $\mathrm{H}_{2} \mathrm{~S}$.

\section{CONFLICT OF INTEREST}

The author declares no conflict of interest.

\section{ACKNOWLEDGEMENTS}

S. Kolemen thanks Koç University for the financial support. The author also acknowledges the researchers in Koç University Surface Science and Technology Center (KUYTAM) for fluorescence quantum yield measurements.

\section{REFERENCES}

1. Qian Y, Karpus J, Kabil O, Zhang S-Y, Zhu H-L, Banerjee $R$, et al. Selective fluorescent probes for live-cell monitoring of sulphide. Nat Commun. 2011 Sep;2(1):495.

2. Olas B. Hydrogen sulfide in signaling pathways. Clinica Chimica Acta. 2015 Jan;439:212-8.

3. Rose $\mathrm{P}$, Moore $\mathrm{PK}$, Zhu $\mathrm{YZ}$. H2S biosynthesis and catabolism: new insights from molecular studies. Cell Mol Life Sci. 2017 Apr;74(8):1391412 .

4. Wang R. The Gasotransmitter Role of Hydrogen Sulfide. Antioxidants \& Redox Signaling. 2003 Aug;5(4):493-501.

5. Papapetropoulos A, Pyriochou A, Altaany Z, Yang G, Marazioti A, Zhou Z, et al. Hydrogen sulfide is an endogenous stimulator of angiogenesis. Proceedings of the National Academy of Sciences. 2009 Dec 22;106(51):21972-7.

6. Wei H-J, Li X, Tang X-Q. Therapeutic benefits of $\mathrm{H} 2 \mathrm{~S}$ in Alzheimer's disease. Journal of Clinical Neuroscience. 2014 Oct 1;21(10):1665-9.

7. Szabó C. Hydrogen sulphide and its therapeutic potential. Nature Reviews Drug Discovery. 2007 Nov $1 ; 6(11): 917-35$.

8. Kamoun $\mathrm{P}$, Belardinelli $\mathrm{M}-\mathrm{C}$, Chabli A, Lallouchi $K$, Chadefaux-Vekemans $B$. Endogenous hydrogen sulfide overproduction in Down syndrome.
American journal of medical genetics. $2003 ; 116(3): 310-1$.

9. Wang L, Cai H, Hu Y, Liu F, Huang $S$, Zhou $Y$, et al. A pharmacological probe identifies cystathionine $\beta$-synthase as a new negative regulator for ferroptosis. Cell Death Dis. 2018 Oct;9(10):1005.

10. Breza J, Soltysova A, Hudecova S, Penesova A, Szadvari I, Babula $P$, et al. Endogenous H2S producing enzymes are involved in apoptosis induction in clear cell renal cell carcinoma. BMC Cancer. 2018 May 24;18(1):591.

11. Lawrence NS, Davis J, Jiang L, Jones TGJ, Davies SN, Compton RG. The Electrochemical Analog of the Methylene Blue Reaction: A Novel Amperometric Approach to the Detection of Hydrogen Sulfide. Electroanal. 2000;12(18):145360.

12. Choi MG, Cha S, Lee $H$, Jeon HL, Chang S-K. Sulfide-selective chemosignaling by a $\mathrm{Cu} 2+$ complex of dipicolylamine appended fluorescein. Chem Commun. 2009;(47):7390.

13. Furne J, Saeed A, Levitt MD. Whole tissue hydrogen sulfide concentrations are orders of magnitude lower than presently accepted values. American Journal of Physiology-Regulatory, Integrative and Comparative Physiology. 2008 Nov;295(5):R1479-85.

14. Qian $Y$, Zhang L, Ding S, Deng $X$, He C, Zheng $X E$, et al. A fluorescent probe for rapid detection of hydrogen sulfide in blood plasma and brain tissues in mice. Chem Sci. 2012;3(10):2920.

15. Lin VS, Chen W, Xian M, Chang CJ. Chemical probes for molecular imaging and detection of hydrogen sulfide and reactive sulfur species in biological systems. Chem Soc Rev. 2015;44:4596618.

16. Liu C, Pan J, Li S, Zhao Y, Wu LY, Berkman CE, et al. Capture and Visualization of Hydrogen Sulfide by a Fluorescent Probe. Angew Chem. 2011 Oct $24 ; 123(44): 10511-3$.

17. Lippert AR, New EJ, Chang CJ. Reaction-Based Fluorescent Probes for Selective Imaging of Hydrogen Sulfide in Living Cells. J Am Chem Soc. 2011 Jul 6;133(26):10078-80.

18. Liu $Y$, Feng G. A visible light excitable colorimetric and fluorescent ESIPT probe for rapid and selective detection of hydrogen sulfide. Org Biomol Chem. 2014;12:438-45. 
19. Guo Z, Park S, Yoon J, Shin I. Recent progress in the development of near-infrared fluorescent probes for bioimaging applications. Chem Soc Rev. 2014;43(1):16-29.

20. Gong S, Zhou E, Hong J, Feng G. Nitrobenzoxadiazole Ether-Based Near-Infrared Fluorescent Probe with Unexpected High Selectivity for $\mathrm{H} 2 \mathrm{~S}$ Imaging in Living Cells and Mice. Anal Chem. 2019 Oct 15;91(20):13136-42.

21. Ozdemir T, Sozmen F, Mamur S, Tekinay T, Akkaya EU. Fast responding and selective near-IR Bodipy dye for hydrogen sulfide sensing. Chem Commun. 2014;50:5455-7.

22. Zheng $Y$, Zhao $M$, Qiao Q, Liu $H$, Lang $H, X u Z$. A near-infrared fluorescent probe for hydrogen sulfide in living cells. Dyes and Pigments. 2013 Sep $1 ; 98(3): 367-71$.

23. Zhang $X$, Zhang L, Ma W-W, Zhou Y, Lu Z-N, $\mathrm{Xu}$ S. A Near-Infrared Ratiometric Fluorescent Probe for Highly Selective Recognition and Bioimaging of Cysteine. Frontiers in Chemistry. 2019;7:32.

24. Karton-Lifshin N, Albertazzi L, Bendikov $M$, Baran PS, Shabat D. "Donor-Two-Acceptor" Dye Design: A Distinct Gateway to NIR Fluorescence. ] Am Chem Soc. 2012 Dec 19;134(50):20412-20.

25. Chen C, Fang C. Devising Efficient Red-Shifting Strategies for Bioimaging: A Generalizable Donor-
Acceptor Fluorophore Prototype. Chem Asian J. 2020;15:1514-23.

26. Jaswal S, Kumar J. Review on fluorescent donor-acceptor conjugated system as molecular probes. Materials Today: Proceedings. $2020 ; 26: 566-80$.

27. Woo S-J, Kim Y, Kim M-J, Baek JY, Kwon S-K, $\mathrm{Kim} \mathrm{Y}-\mathrm{H}$, et al. Strategies for the Molecular Design of Donor-Acceptor-type Fluorescent Emitters for Efficient Deep Blue Organic Light Emitting Diodes. Chem Mater. 2018 ubat;30(3):857-63.

28. Gong Y, Feng D, Liu W, Fang J, Feng S. A selfimmolative near-infrared probe based on hemibenzothiazolecyanine for visualizing hydrogen peroxide in living cells and mice. Dyes and Pigments. 2021 Feb;186:108954.

29. Zhang $X$, Liu J-Y. Solvent dependent photophysical properties and near-infrared solidstate excited state intramolecular proton transfer (ESIPT) fluorescence of 2,4,6trisbenzothiazolylphenol. Dyes and Pigments. 2016 ubat; 125:80-8.

30. Li S-J, Li Y-F, Liu H-W, Zhou D-Y, Jiang W-L, Ou-Yang J, et al. A Dual-Response Fluorescent Probe for the Detection of Viscosity and H 2 S and Its Application in Studying Their Cross-Talk Influence in Mitochondria. Anal Chem. 2018 Aug 7;90(15):9418-25. 


\section{SUPPLEMENTARY INFORMATION}

\section{A Near-infrared Benzothiazole-based Chemodosimeter for Rapid and Selective Detection of Hydrogen Sulfide}

\section{Safacan KOLEMEN ${ }^{1,2,3 *}$}

${ }^{1}$ Department of Chemistry, Faculty of Science, Koc University, Sariyer, Istanbul 34450, Turkey

${ }^{2}$ Surface Science and Technology Center (KUYTAM), Koc University, Sariyer, Istanbul 34450, Turkey

${ }^{3}$ Boron and Advanced Materials Application and Research Center, Koc University, Sariyer, Istanbul 34450, Turkey

\section{NMR Spectra}

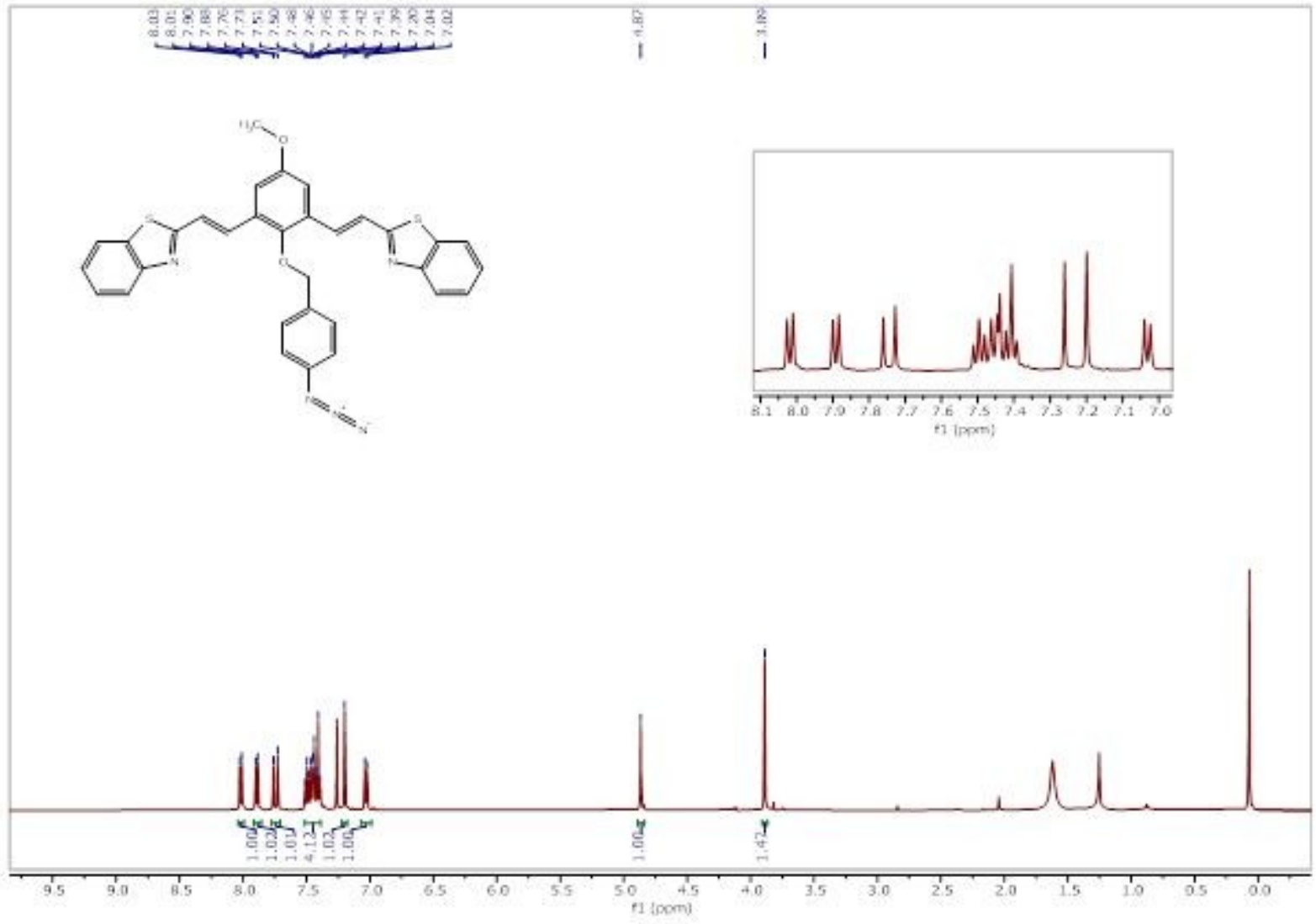

Figure S1. ${ }^{1} \mathrm{H}$ NMR spectrum of HP-1. 


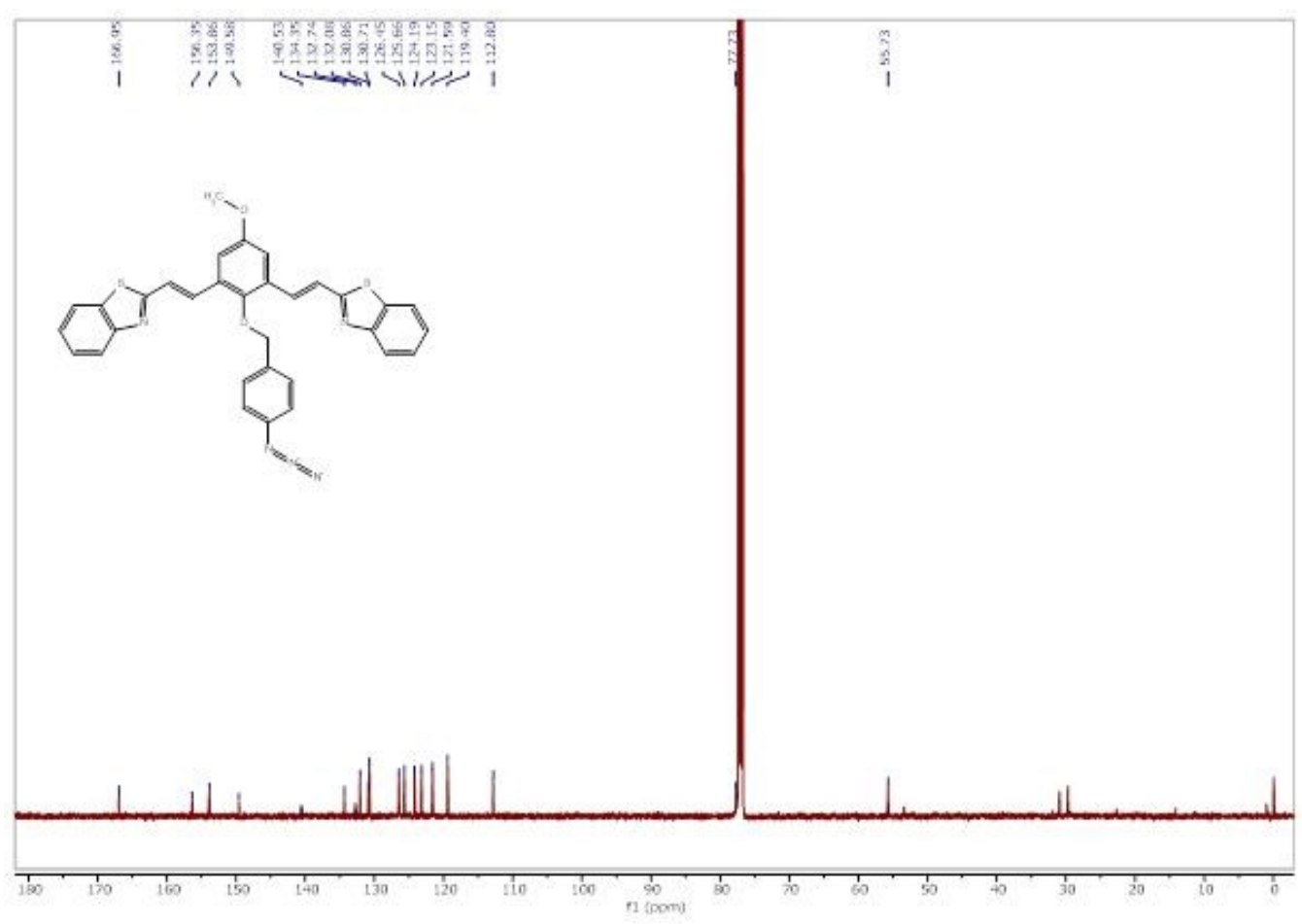

Figure S2. ${ }^{13} \mathrm{C}$ NMR spectrum of HP-1.

\section{Mass Spectra}

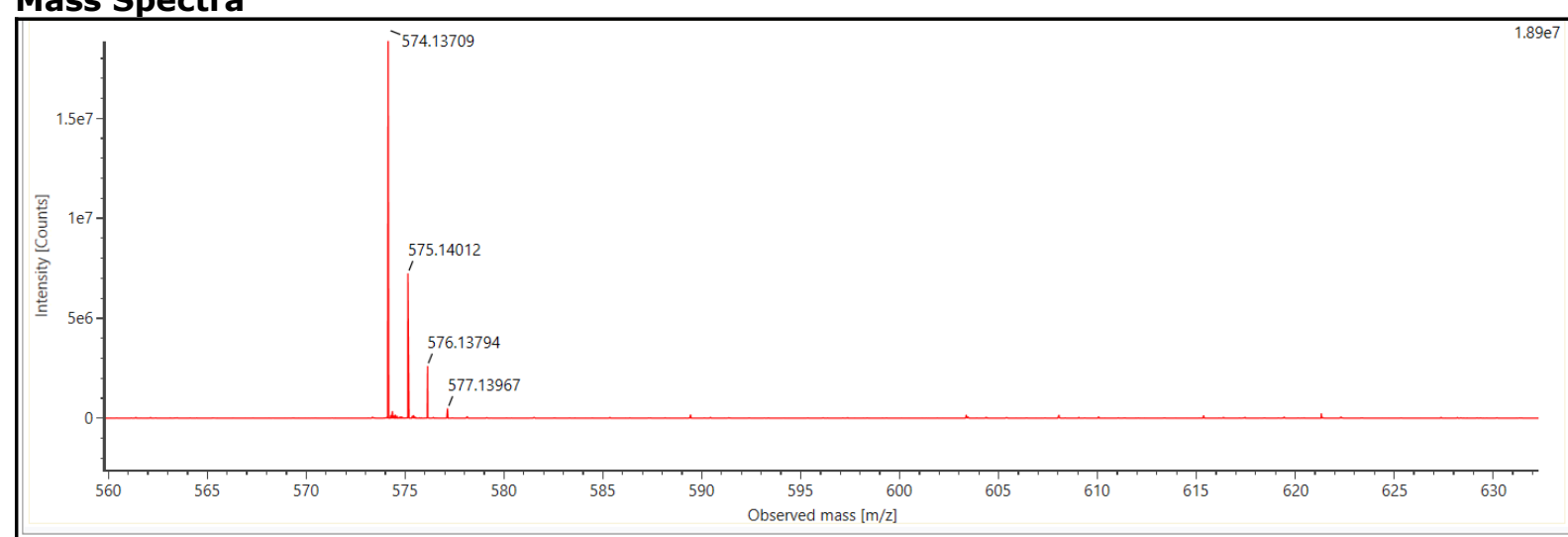

Figure S3. HR-MS spectrum of HP-1.

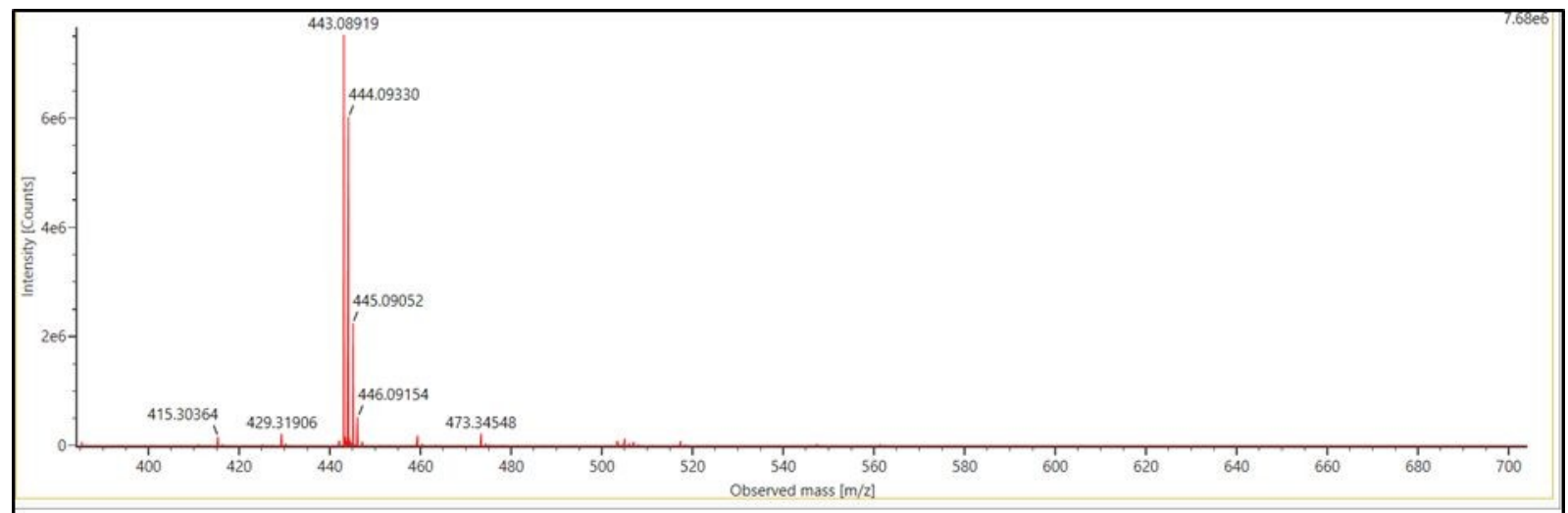

Figure S4. HR-MS spectrum of HP-1 $+\mathrm{Na}_{2} \mathrm{~S}$. Calc. for $\mathrm{C}_{25} \mathrm{H}_{18} \mathrm{~N}_{2} \mathrm{O}_{2} \mathrm{~S}_{2} 443.0810[\mathrm{M}+\mathrm{H}]^{+}$; found: 443.0892. 


\section{Photophysical characterization}
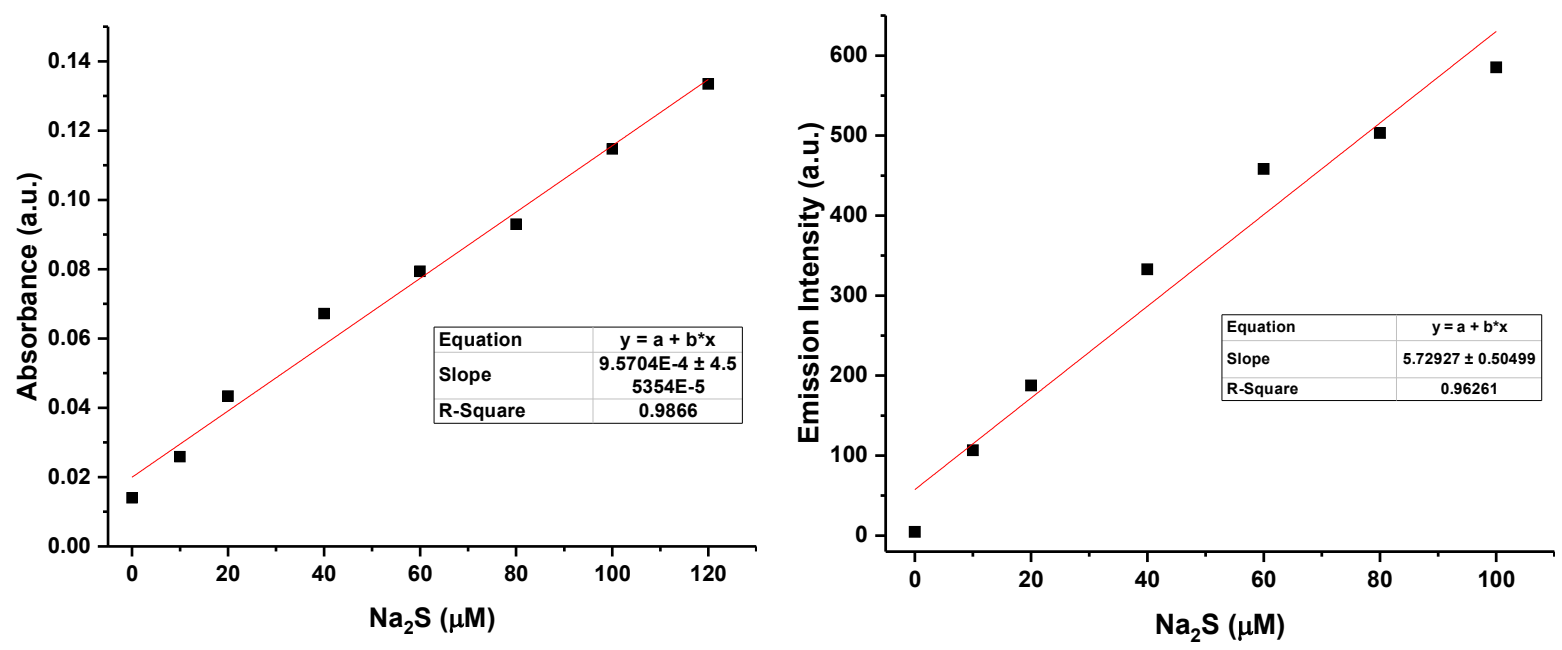

Figure S5. Increase of the absorption signal (left) of HP-1 $(20 \mu \mathrm{M})$ at $530 \mathrm{~nm}$ and emission signal (right) at $680 \mathrm{~nm}$ in increasing $\mathrm{Na}_{2} \mathrm{~S}$ concentrations in PBS (pH 7.4,50\% DMF) in the linear concentration range. 
Kolemen S. JOTCSA. 2021: 8(2): 567-578.

RESEARCH ARTICLE 